Gournal of Science
PART C: DESIGN AND TECHNOLOGY
http://dergipark.gov.tr/gujsc

\title{
Comparison of Control Techniques for Series Resonant Converter
}

\author{
Salih NACAR ${ }^{1, *}$ (D) Selim ÖNCÜ2 ${ }^{2}$ Güngör BAL ${ }^{3}$ (D) \\ ${ }^{1}$ Kastamonu University, Taşköprü Vocational School, Department of Electric and Energy, 37400, Taşköprü/KASTAMONU \\ ${ }^{2}$ Karabük University, Faculty of Engineering, Department of Electrical and Electronics Engineering, 78050, Balkklarkayasl/KARABÜK \\ ${ }^{3}$ Gazi University, Faculty of Technology, Department of Electrical and Electronics Engineering, 06500, Yenimahalle/ANKARA
}

\begin{tabular}{l} 
Article Info \\
\hline Research article \\
Received:02/04/2021 \\
Revision: $14 / 05 / 2021$ \\
Accepted:17/05/2020 \\
Keywords \\
Resonant Converters \\
Control Techniques \\
FM \\
PSM \\
PDM
\end{tabular}

Article Info

Received:02/04/2021

Revision:14/05/2021

Accepted:17/05/2020

$P D M$

\begin{abstract}
There are many different derivatives of variable and fixed frequency switching control techniques used in control of load resonant converters. In this study; among these techniques frequency modulation (FM), phase shift modulation (PSM) and pulse density modulation (PDM) are applied separately to series resonant converter (SRC). The techniques are examined and compared in many respects. An experimental setup is built, which consists of a $400 \mathrm{~W}$ converter, a control circuit and a resistive load to verify theoretical studies. The converter is controlled by FM, PSM and PDM separately for $120 \mathrm{kHz}$ basic operating frequency and different output currents. Experimental results are compared in terms of efficiency, output voltage ripple, soft switching, switch voltage, ease of application and hardware. The comparison results are presented. Thus, effect of each technique on the operating parameters of the converter is revealed. Moreover, it is also observed that FM has better performance than the other two techniques in many aspects
\end{abstract}

\section{INTRODUCTION}

Efficiency of load resonant converters is affected by input voltage and output current levels of different applications in which they are used. Another factor that has an effect on the efficiency is techniques used in control of these converters [1]. The techniques can be divided into variable frequency switching and fixed frequency switching, which have different applications, for instance FM and PSM. While FM is the variable frequency switching control technique, PSM is the fixed frequency switching control technique. The both are traditional methods [2]. PDM is one of the fixed frequency switching techniques, which is frequently used in control of resonant inverters as well as DC-DC converters [3, 4].

Output power control with FM is performed by changing switching frequency $\left(\mathrm{f}_{\mathrm{s}}\right)$. In the FM, when it is desired to decrease the output power while operating above the resonance frequency $\left(f_{r}\right)$, it is necessary to increase the switching frequency. However, with increasing switching frequency, switching losses and electromagnetic interference (EMI) also increase. Therefore, changing the switching frequency for the output power control is the disadvantage for the FM. In addition, when operating below the resonance frequency, filter design becomes difficult due to the changing switching frequency [5-8]. Despite these disadvantages, its simple structure and easy applicability are the advantages of FM $[9,10]$.

Changing the duty ratio of the inverter voltage, which defines the effective value of the inverter voltage, performs the power control in PSM. As long as the resonance current is lagging with respect to the inverter voltage, the switches are turned on under soft switching conditions. However as the duty ratio of inverter voltage is decreased, the resonance current is leading with respect to the inverter voltage. As a result, soft switching conditions of some switches are disappeared and the switching losses increase [1012]. The disadvantage of PSM is that the soft switching conditions of some switches are disappeared as the load current decreases. Operation at fixed switching frequency is the advantage of PSM. 
PDM control can be divided into two groups as regular and irregular, the power control is performed by deleting some of switching pulses [13]. PDM is especially used in induction heating applications [14-16]. Main reason for this is that the system response does not need to be fast since the work piece temperature controlled in this application does not change rapidly. Therefore, fast output response is not required unlike DC-DC converters. Disadvantages of the regular PDM are that the varying of damping time depending on the quality factor of the resonance current causes the fluctuations in the output power and the peak value of the resonance current is much bigger than the other two techniques, especially with the decreasing load current $[17,18]$. In order to eliminate these disadvantages of the regular PDM method, the irregular PDM is recommended. By maintaining the oscillation of the resonance current with the irregular PDM, phase locking loop continues to operate and the changes in the resonance current are reduced. Thus, the fluctuations in the power transferred to the load are reduced. Amount of sub harmonics also decreases with the irregular PDM. However, this method requires complex and large logic circuits or memory elements to obtain gate signals of the power switches [19-22]. In the regular PDM, the control signals of the power switches can be obtained by simple logic circuits [23].

There are also hybrid applications of FM, PSM and PDM used for the power control of the load resonant converter [24-26]. In these applications, the power control is performed with more than one technique by benefiting from the advantages of each technique for different load conditions. Thus, the decreasing converter efficiency is prevented, especially in light loads. However, as a result of using more than one technique together, complexity, application difficulty and components of the control unit increase.

SRCs have a suitable structure for half and full-bridge applications. The full-bridge, which is more suitable for application of different control techniques, is preferred in this study. Because of the advantages of operating above the resonance frequency at high frequencies, the switching frequency of the full-bridge SRC is selected above the resonance frequency and MOSFETs are used as power switches. A 16-bit dsPIC33FJ16GS502 digital signal controller (DSC) is used to execute the control algorithm, generate the control signals of the switches and digitize the feedback information.

\section{CONTROL OF THE FULL-BRIDGE SERIES RESONANT CONVERTERS}

The isolated full-bridge SRC and control circuit used in experimental studies are shown in Figure 1. A lot of different control techniques such as FM, PSM and PDM are used to control the converter [3, 27, 28].

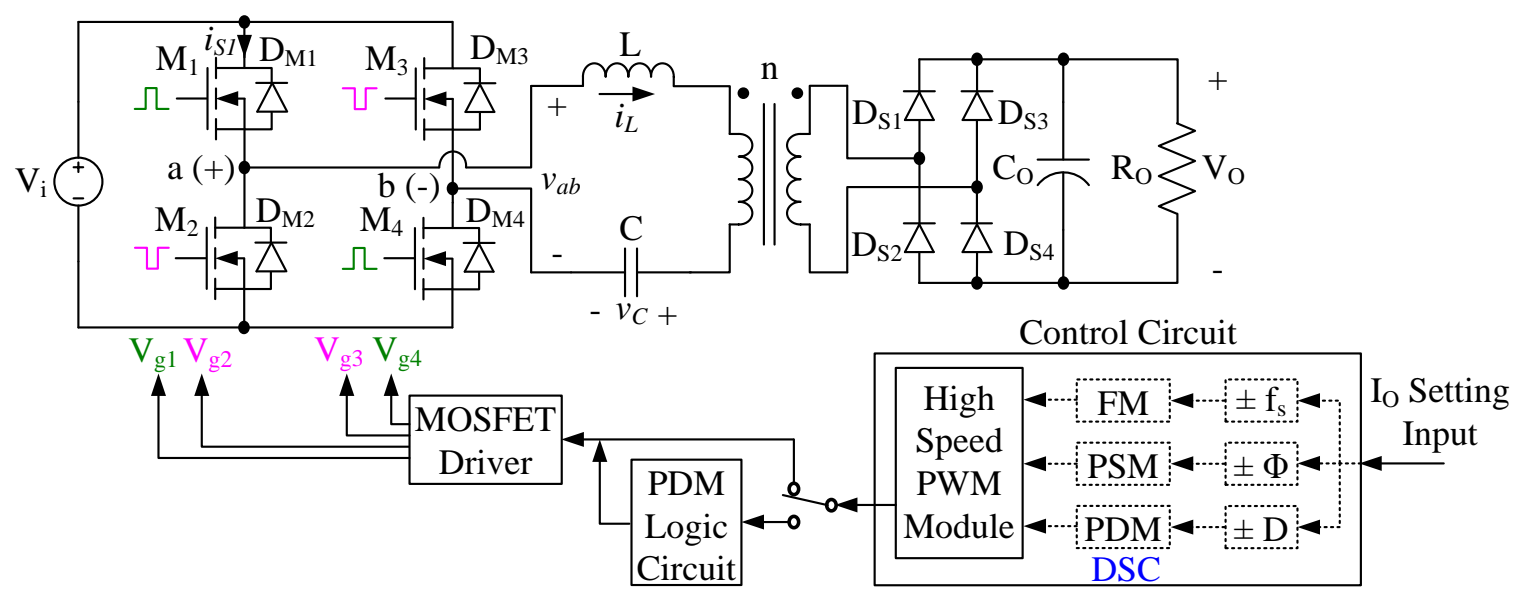

Figure 1. The isolated full-bridge SRC and control circuit

The classification of these techniques is given in the following sections.

\subsection{Variable Frequency Control}

Different derivatives of the variable frequency switching control technique are as follows:

- Frequency modulation 
- Average current

- Capacitor voltage

- Diode conduction angle

- Optimal curve control

Among these techniques, FM is the most preferred technique because of its simple structure and easy application [5]. Gate signals $\mathrm{V}_{\mathrm{gl} 1 \mathrm{~g} 4}$, theoretical waveforms of the inverter voltage $\mathrm{v}_{\mathrm{ab}}$ and current $\mathrm{i}_{\mathrm{L}}$ of FM controlled converter are given in Figure 2a.

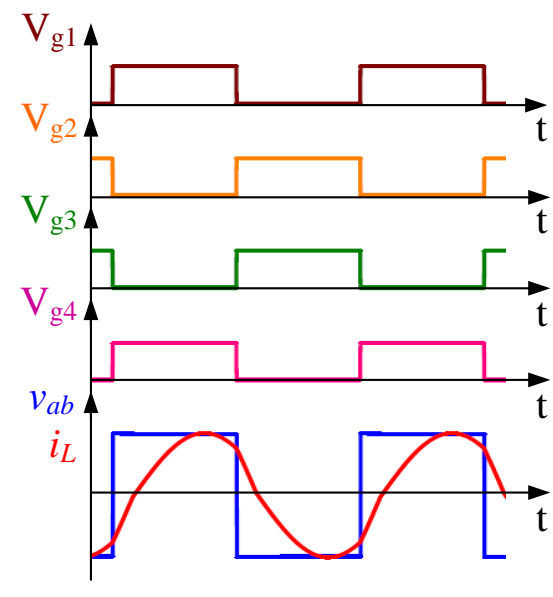

a)

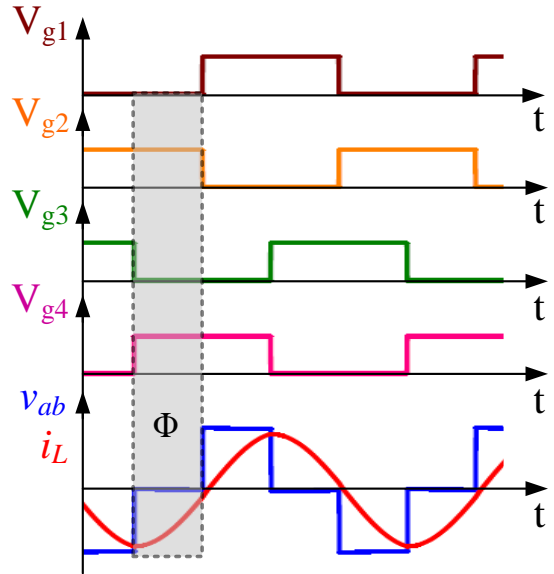

b)

Figure 2. Waveforms of FM and PSM controlled converter, a) FM, b) PSM

While changing the switching frequency that is the control variable of this technique controls the load current, the duty ratio and peak value of the inverter voltage remain constant. In addition, the converter has four different operating intervals in steady-state conditions. Since the current is lagging in all of these operating intervals, the power switches are turned off under hard switching while they are turned on under zero voltage switching (ZVS).

\subsection{Fixed Frequency Switching Control}

Although the fixed frequency switching technique has different derivatives [1, 2], the control variables in these techniques differ in contrast to the variable frequency control technique. Among these techniques; PSM and PDM are frequently used in the control of resonant converters and resonant inverters, respectively.

- Phase shift modulation

- Asymmetric phase shift modulation

- Asymmetric duty ratio

- Unipolar voltage cancellation

- Secondary party

- Pulse density modulation

\subsubsection{Phase Shift Control}

Generally PSM is preferred to avoid the variable frequency switching for the power control and to operate at the fixed switching frequency [10-12]. The power control in PSM is accomplished by varying the duty ratio of the inverter voltage. Gate signals of the power switches, inverter voltage and current waveforms of PSM controlled converter are given in Figure $2 \mathrm{~b}$. The duty ratio of the inverter voltage is obtained by changing the angle $\Phi$, which is the phase difference between the gate signals of the diagonal power switches. Since the angle $\Phi$ is the control variable, it is changed from 0 to 180 degrees to control the output current. In PSM, the output current decreases as the phase angle $\Phi$ increases. The three different 
operating states occur with the decrease of the output current of PSM controlled converter [27, 28]. In one of these states, all of the power switches are turned on under ZVS conditions and the current is lagging. This operating state is preferred because of the higher efficiency, especially in applications where MOSFET is used as the power switch at high frequencies [27].

\subsubsection{Pulse Density Modulation Control}

In a PDM, the switching losses can be reduced by operating at the resonance frequency or at a frequency close to the resonance frequency. The regular PDM is used in the experimental studies due to its simple control circuit structure and easy applicability. The application of the regular PDM is given in Figure 3. PWM pulses and the control signal are applied to the synchronization circuit to synchronize control and PWM signals and then the synchronization circuit output and PWM pulses are applied to AND gate to determine number of PWM pulses used to drive the power switch.

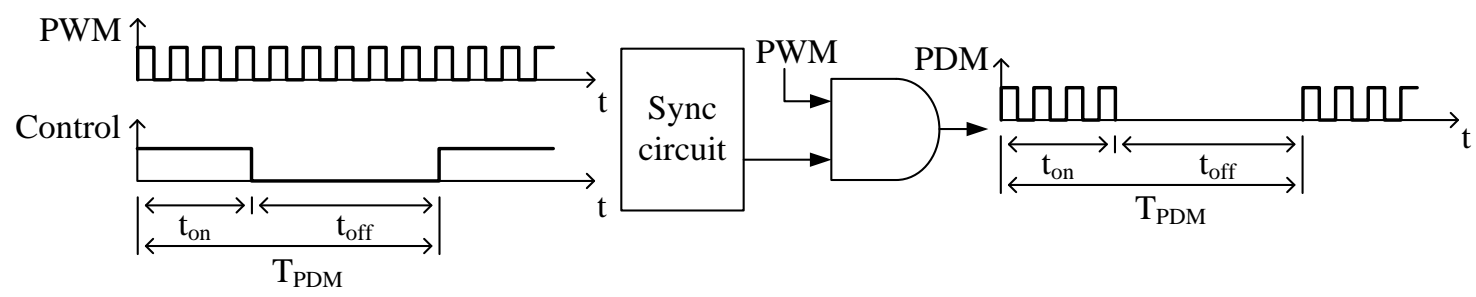

Figure 3. The generation of the regular PDM signals

PDM control is accomplished by changing the duty ratio D of the control signal given in Equation 1. Hence, the control variable is the duty ratio of the control signal.

$$
D=\frac{t_{o n}}{T_{P D M}}
$$

In FM and PSM, gate signals of the power switches can be obtained with analog integrated circuits or programmable circuit elements such as microcontrollers [29-31]. The logic circuit or memory elements are required to obtain gate signals of the power switches in the regular or irregular PDM [18-22]. The logic control circuit of the regular PDM used in experimental studies is given in Figure 4a.

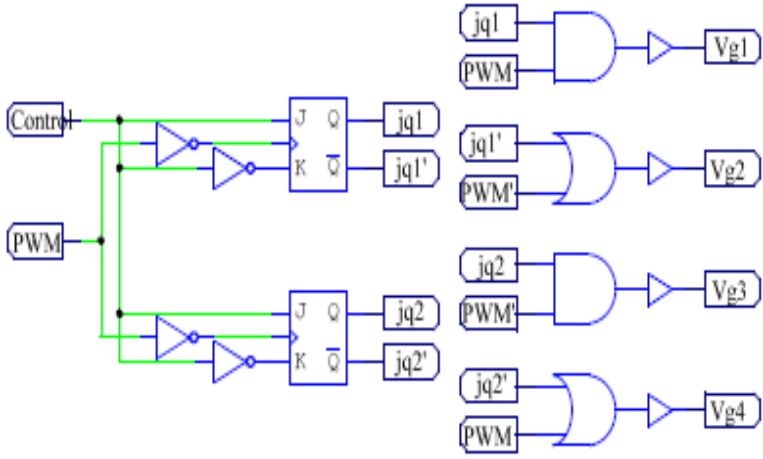

a)

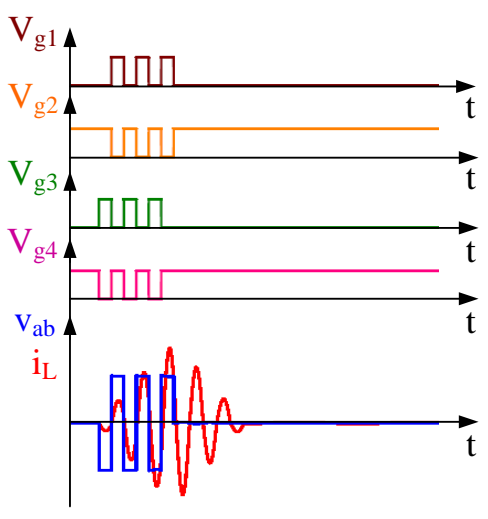

b)

Figure 4. The logic circuit used to obtain the regular PDM signals and the waveforms of regular PDM controlled converter, a) logic circuit, $b$ ) the waveforms

Gate signals of the power switches, waveforms of the inverter voltage and current for PDM controlled converter are given in Figure $4 \mathrm{~b}$. For operating above the resonance frequency, $t_{\text {on }}$ interval operation of PDM controlled converter is same as FM controlled converter. However, by keeping the power switches 
$\mathrm{M}_{2}$ and $\mathrm{M}_{4}$ in conduction throughout $\mathrm{t}_{\mathrm{off}}$, the inverter voltage becomes zero. Therefore, there is no energy transfer from the source to the load at $\mathrm{t}_{\text {off }}$ interval.

\section{TEST RESULTS OF DIFFERENT CONTROL TECHNIQUES FOR RESISTIVE LOAD}

In this study for purpose of comparison of three different control techniques named as FM, PSM and PDM, the experimental set up is built as given in Figure 5. The converter and control circuit on the same board used to control the output current separately with three different techniques are given in Figure 6.

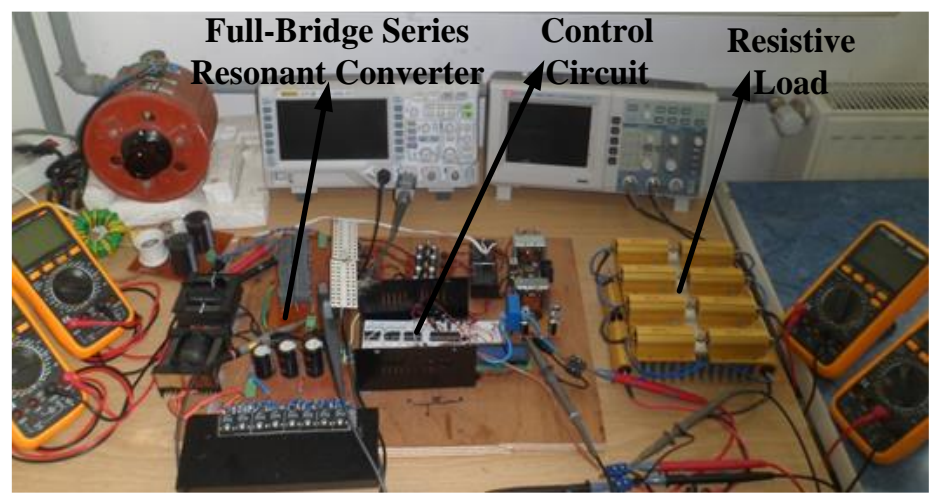

Figure 5. The experimental setup

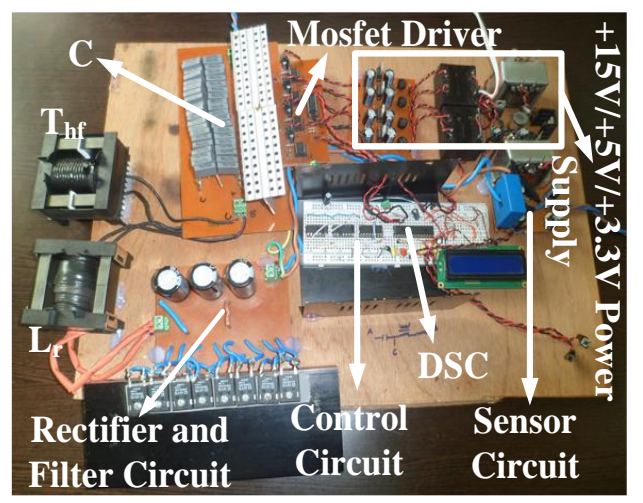

Figure 6. The converter circuit

The parameters of the converter are as given in Table 1.

Table 1. The parameters of the converter

\begin{tabular}{|l|l|l|l|l|l|}
\hline $\mathrm{V}_{\mathrm{i}}=200 \mathrm{~V}$ & $\mathrm{n}=18: 4$ & $\mathrm{~L}=191 \mu \mathrm{H}$ & $\mathrm{C}=10 \mathrm{nF}$ & $\mathrm{f}_{\mathrm{r}}=115 \mathrm{kHz}$ & $\mathrm{R}_{\mathrm{O}}=3.33 \Omega$ \\
\hline
\end{tabular}

The output voltage, current and power of the converter for $120 \mathrm{kHz}$ fixed operating frequency are $36.4 \mathrm{~V}$, $10.8 \mathrm{~A}$ and $393.12 \mathrm{~W}$, respectively. Gate signals of the power switches, inverter voltage and current waveforms of the converter are given in Figure 7 for $120 \mathrm{kHz}$.

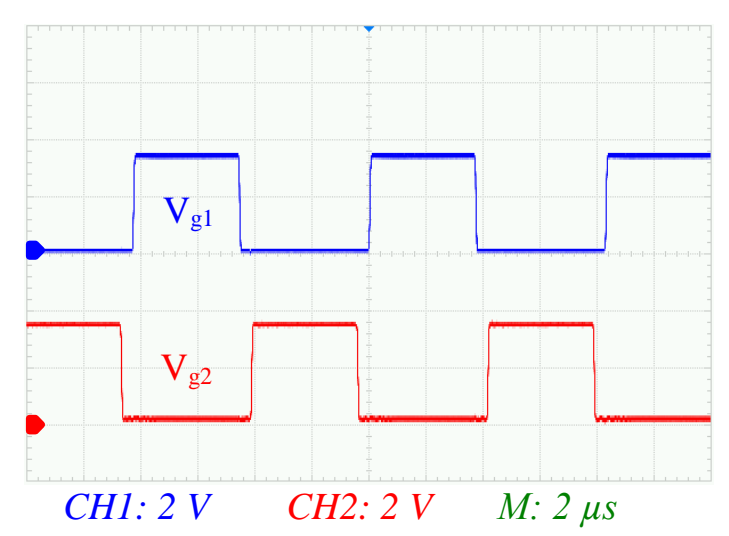

a)

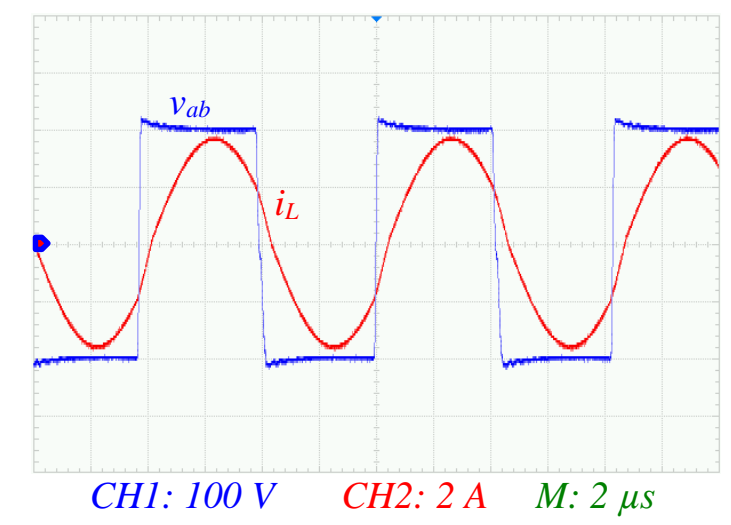

b)

Figure 7. Gate signals of the power switches, inverter voltage and current for $120 \mathrm{kHz}$, a) gate signals of the power switches, $b$ ) the inverter voltage and current

In order to compare the techniques, the load current of the converter is controlled separately by each control technique in $1 \mathrm{~A}$ intervals from $4 \mathrm{~A}$ to $10 \mathrm{~A}$. The input current $\left(\mathrm{I}_{\mathrm{i}}\right)$, input voltage $\left(\mathrm{V}_{\mathrm{i}}\right)$, inverter current $\left(\mathrm{i}_{\mathrm{L}}\right)$ and voltage $\left(\mathrm{v}_{\mathrm{ab}}\right)$, output current $\left(\mathrm{I}_{\mathrm{O}}\right)$, output voltage $\left(\mathrm{V}_{\mathrm{O}}\right)$ and output voltage ripple $\left(\Delta \mathrm{V}_{\mathrm{O}}\right)$ are measured and recorded for each determined output current value. While $\mathrm{I}_{\mathrm{i}}, \mathrm{V}_{\mathrm{i}}, \mathrm{I}_{\mathrm{O}}$ and $\mathrm{V}_{\mathrm{O}}$ are measured by a digital multimeter, $\mathrm{i}_{\mathrm{L}}$ is measured by a Tektronix 011-0105-00 AC current probe. 


\subsection{Frequency Controlled Converter}

Gate signals of the power switches of FM controlled converter are obtained by using a pair speed PWM module and two output pins of DSC. The output current is controlled from 4 A to $10 \mathrm{~A}$ by changing the switching frequency of the converter between $187.97 \mathrm{kHz}$ and $125.63 \mathrm{kHz}$. The waveforms of the inverter voltage and current for these output currents are given in Figure 8.

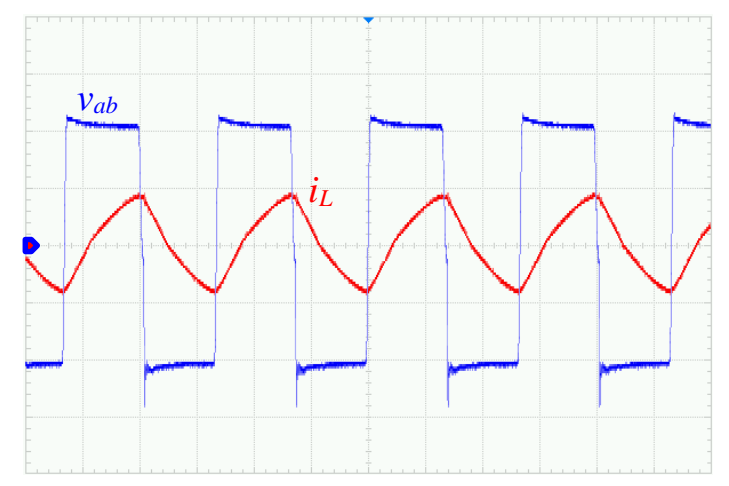

a)

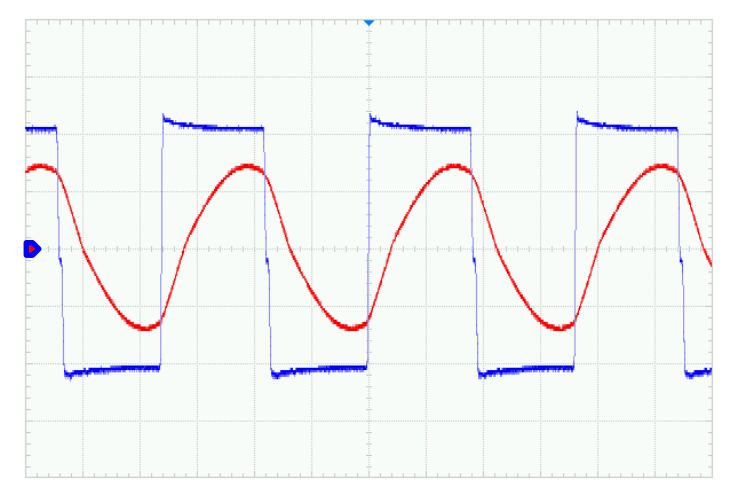

c)

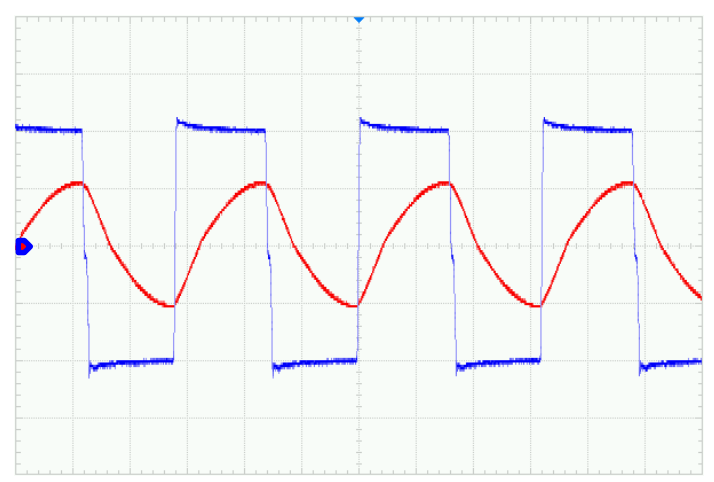

b)

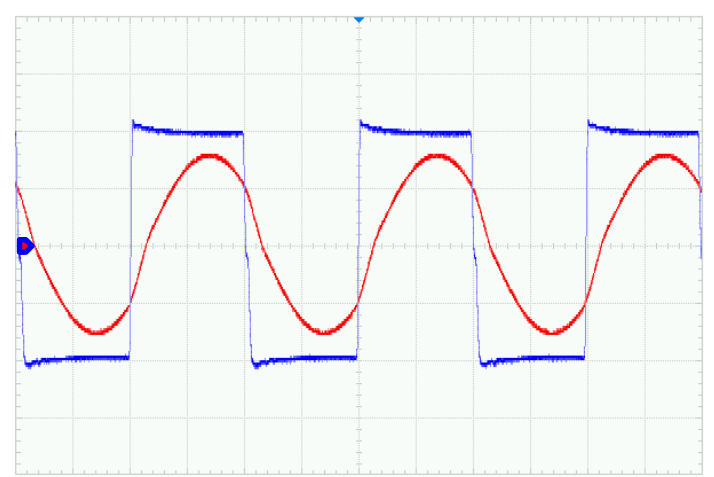

d)

Figure 8. The inverter voltage and current of FM controlled converter for the different output currents (CH1: $100 \mathrm{~V}, \mathrm{CH} 2: 2 \mathrm{~A}$ and $\mathrm{M}: 2 \mu \mathrm{s}), a) 4 \mathrm{~A}, b) 6 \mathrm{~A}, c) 8 \mathrm{~A}, d) 10 \mathrm{~A}$

An increase of $62.34 \mathrm{kHz}$ is required in the switching frequency to reduce the output current from $10 \mathrm{~A}$ to $4 \mathrm{~A}$ in FM controlled converter. While the power switches are turned on under ZVS conditions, they are turned off under hard switching. The voltage $\left(v_{\mathrm{S} 4}\right)$ and current $\left(i_{\mathrm{S} 4}\right)$ of the switch $\mathrm{M}_{4}$ are given in Figure 9 for $10 \mathrm{~A}$.

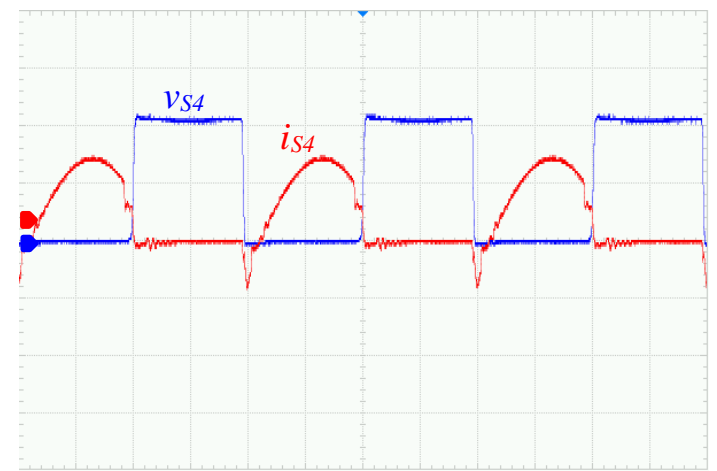

Figure 9. The voltage $\left(v_{S 4}\right)$ and current $\left(i_{S 4}\right)$ of $M_{4}$ for $10 \mathrm{~A}(\mathrm{CH}: 100 \mathrm{~V}, \mathrm{CH} 2: 2 \mathrm{~A}$ and $\mathrm{M}: 2 \mu \mathrm{s})$ 
The results summarizing the operation of FM controlled converter for the different output currents are given in Table 2.

Table 2. Operation parameters of FM controlled converter

\begin{tabular}{|c|c|c|c|c|c|c|c|c|}
\hline $\begin{array}{c}\mathrm{V}_{\mathrm{i}} \\
(\mathrm{V})\end{array}$ & $\mathrm{I}_{\mathrm{i}}(\mathrm{A})$ & $\begin{array}{c}\mathrm{V}_{\mathrm{O}} \\
(\mathrm{V})\end{array}$ & $\begin{array}{c}\mathrm{I}_{\mathrm{O}} \\
(\mathrm{A})\end{array}$ & $\begin{array}{c}\text { Efficiency } \\
(\%)\end{array}$ & $\begin{array}{c}\Delta \mathrm{V}_{\mathrm{O}} / \\
\mathrm{V}_{\mathrm{O}} \\
(\%)\end{array}$ & $\begin{array}{c}\mathrm{I}_{\mathrm{Lm}} \\
(\mathrm{A})\end{array}$ & $\begin{array}{c}\text { Frequency } \\
(\mathrm{kHz})\end{array}$ & $\begin{array}{c}\text { Switch } \\
\text { Stresses } \\
(\mathrm{V})\end{array}$ \\
\hline 200 & 0.372 & 14.10 & 4.03 & 76.37 & 4.25 & 1.85 & 187.97 & 280 \\
\hline 200 & 0.524 & 17.00 & 5.01 & 81.26 & 3.82 & 1.97 & 171.23 & 260 \\
\hline 200 & 0.715 & 20.30 & 6.03 & 85.6 & 3.44 & 2.2 & 156.25 & 230 \\
\hline 200 & 0.957 & 23.50 & 7.02 & 86.19 & 3.19 & 2.48 & 146.2 & 230 \\
\hline 200 & 1.236 & 26.90 & 8.02 & 87.27 & 3.71 & 2.92 & 138.12 & 230 \\
\hline 200 & 1.561 & 30.30 & 9.03 & 87.63 & 4.62 & 3.08 & 130.89 & 220 \\
\hline 200 & 1.905 & 33.50 & 10.02 & 88.1 & 5.97 & 3.2 & 125.63 & 220 \\
\hline
\end{tabular}

The efficiency is obtained by dividing the output power $\left(\mathrm{V}_{\mathrm{O}} \mathrm{I}_{\mathrm{O}}\right)$ by the input power $\left(\mathrm{V}_{\mathrm{i}} \mathrm{I}_{\mathrm{i}}\right)$ and it decreases as the switching frequency increases in FM, as seen in Table 2 . The voltage stresses across the switch increase as the output current decreases. However, ZVS is guaranteed from $10 \mathrm{~A}$ to $4 \mathrm{~A}$ as the converter operates above the resonance frequency.

\subsection{Phase Shift Controlled Converter}

Gate signals of the power switches of PSM controlled converter are obtained by using two pair speed PWM module and four output pins of DSC. The inverter voltage and current of the converter whose switching frequency is $120 \mathrm{kHz}$ and output current is controlled by PSM from $4 \mathrm{~A}$ to $10 \mathrm{~A}$, are given in Figure 10.

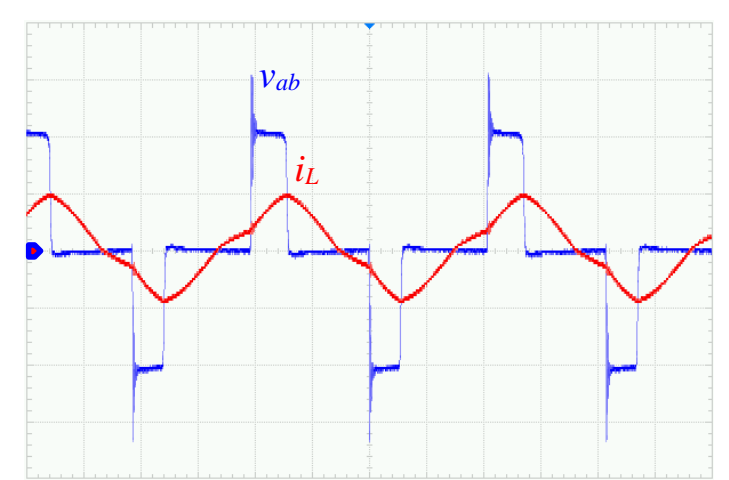

a)

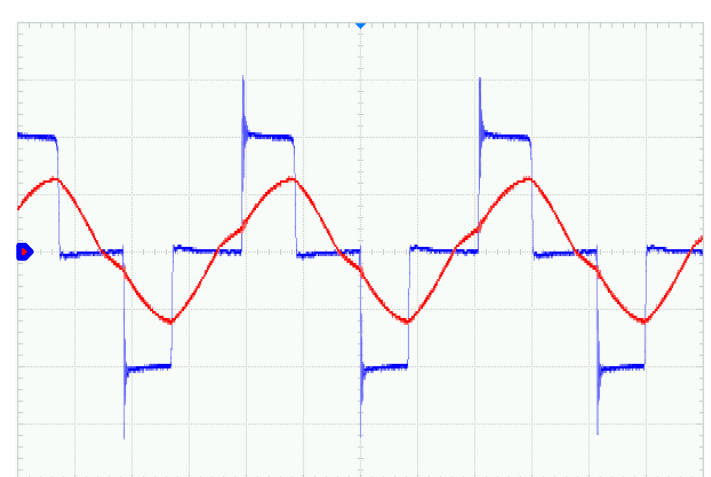

b) 


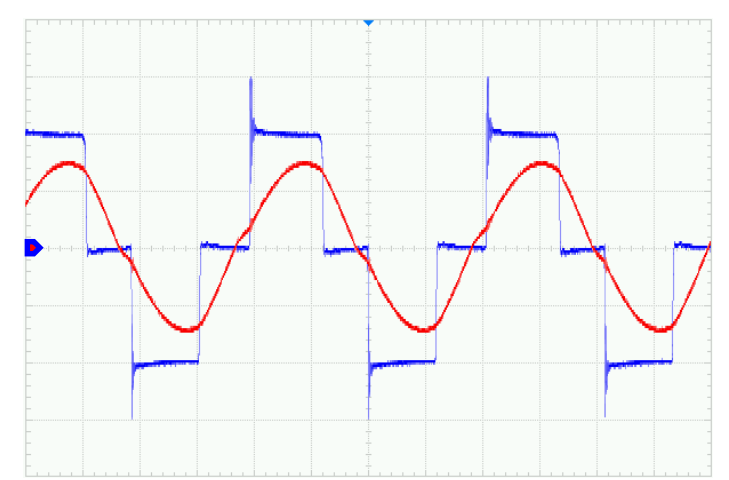

c)

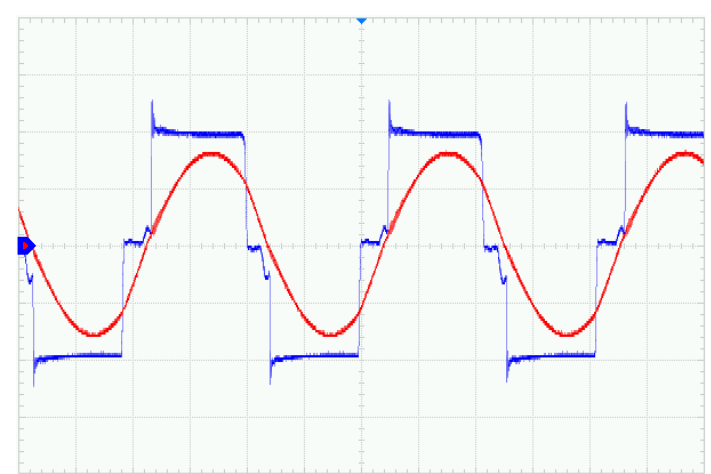

d)

Figure 10. The inverter voltage and current of PSM controlled converter for the different output currents (CH1: $100 \mathrm{~V}, \mathrm{CH} 2: 2 \mathrm{~A}$ and $\mathrm{M}: 2 \mu \mathrm{s}), a) 4 \mathrm{~A}, b) 6 \mathrm{~A}, c) 8 \mathrm{~A}, d) 10 \mathrm{~A}$

Since the phase difference $(\Phi)$ increases with the decreasing output current in PSM controlled converter, the lagging current becomes leading with respect to the inverter voltage. As can be seen from the voltage and current waveforms of $\mathrm{M}_{2}$ and $\mathrm{M}_{4}$ switches given in Figure 11 for $10 \mathrm{~A}$, while the power switches on the left arm of the full-bridge are leading, the power switches on the right arm of the full-bridge are lagging. As a result, ZVS conditions for the power switches on the left arm are disappeared. The switches are turned off under zero current switching conditions and turned on under hard switching. Moreover, the switch stresses increase with increasing the phase difference. On the other hand, while the switches on the right arm are turned on under ZVS, they are turned off under hard switching.

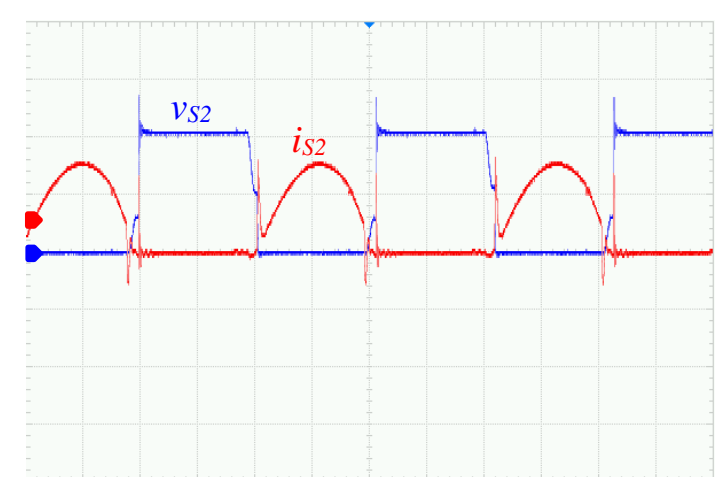

a)

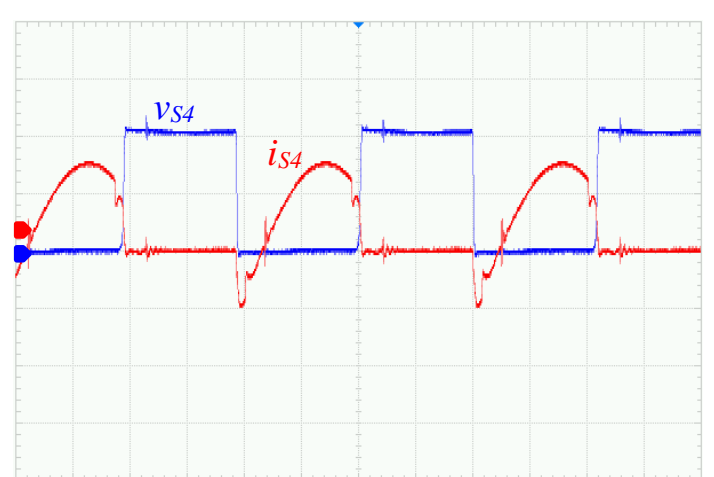

b)

Figure 11. The voltage and current of $\mathrm{M}_{2}$ and $\mathrm{M}_{4}$ for $10 \mathrm{~A}(\mathrm{CH} 1: 100 \mathrm{~V}, \mathrm{CH} 2: 2 \mathrm{~A}$ and $\mathrm{M}: 2 \mu \mathrm{s})$, a) the voltage and current of $\left.M_{2}, b\right)$ the voltage and current of $M_{4}$

The results summarizing the operation of PSM controlled converter for the different output currents are given in Table 3.

Table 3. Operation parameters of PSM controlled converter

\begin{tabular}{|c|c|c|c|c|c|c|c|c|}
\hline $\mathrm{V}_{\mathrm{i}}(\mathrm{V})$ & $\mathrm{I}_{\mathrm{i}}(\mathrm{A})$ & $\mathrm{V}_{\mathrm{O}}(\mathrm{V})$ & $\mathrm{I}_{\mathrm{O}}(\mathrm{A})$ & $\begin{array}{c}\text { Efficiency } \\
(\%)\end{array}$ & $\begin{array}{c}\Delta \mathrm{V}_{\mathrm{O}} / \mathrm{V}_{\mathrm{O}} \\
(\%)\end{array}$ & $\mathrm{I}_{\mathrm{Lm}}(\mathrm{A})$ & $\begin{array}{c}\Phi \text { Phase } \\
\text { Angle }\left({ }^{\circ}\right)\end{array}$ & $\begin{array}{c}\text { Switch } \\
\text { Stresses }(\mathrm{V})\end{array}$ \\
\hline 200 & 0.415 & 14.1 & 4.04 & 68.631 & 3.9 & 1.95 & 118.77 & 340 \\
\hline 200 & 0.625 & 17.5 & 5.04 & 70.56 & 4 & 2.4 & 105.84 & 320 \\
\hline 200 & 0.855 & 20.9 & 6.02 & 73.578 & 4.7 & 2.6 & 92.31 & 320 \\
\hline 200 & 1.13 & 24.4 & 7.03 & 75.899 & 4.9 & 2.9 & 77.77 & 320 \\
\hline
\end{tabular}




\begin{tabular}{|l|c|c|c|c|c|c|c|c|}
\hline 200 & 1.449 & 28.2 & 8.05 & 78.333 & 5.1 & 3.02 & 62.21 & 300 \\
\hline 200 & 1.72 & 31.2 & 9.05 & 82.081 & 5.9 & 3.46 & 47.47 & 310 \\
\hline 200 & 1.982 & 33.8 & 10.06 & 85.779 & 6.8 & 3.3 & 30.52 & 260 \\
\hline
\end{tabular}

As the output current decreases from 10 A in PSM, the switch stresses increase and the efficiency decreases due to disappeared ZVS conditions of the switches $\left(M_{1}, M_{2}\right)$ on the left arm.

\subsection{Pulse Density Controlled Converter}

The frequency of PDM control signal is $8.22 \mathrm{kHz}$ and the switching frequency is $120 \mathrm{kHz}$. Two pair speed PWM modules and four output pins of DSC and the additional logic circuitry are used to obtain gate signals of the power switches. The inverter voltage and current waveforms of PDM controlled converter for different output currents are given in Figure 12.

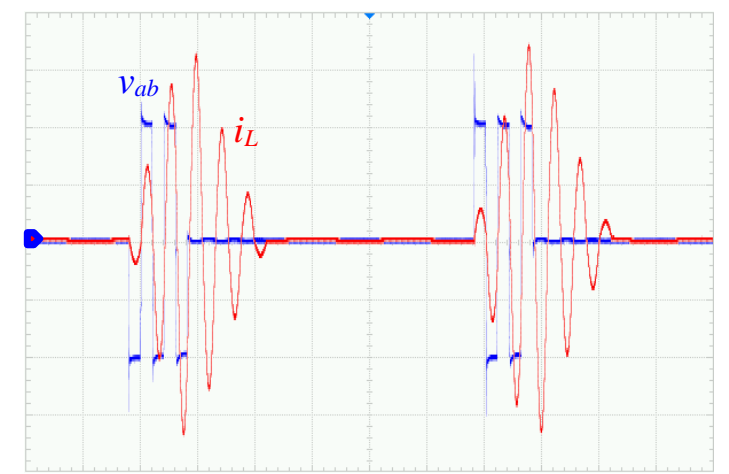

a)

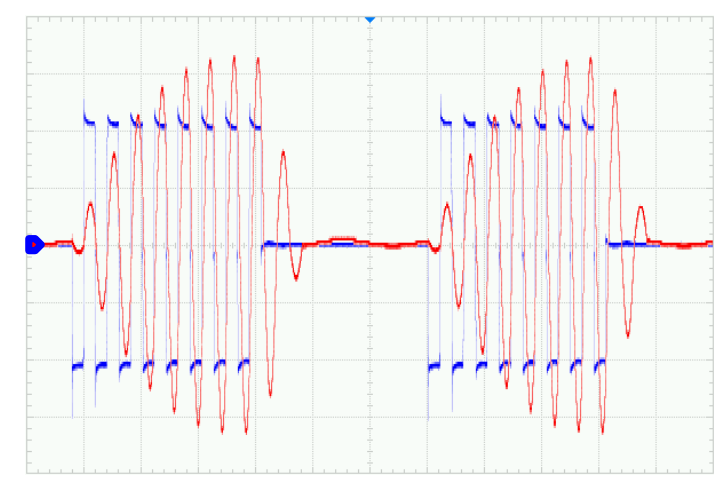

c)

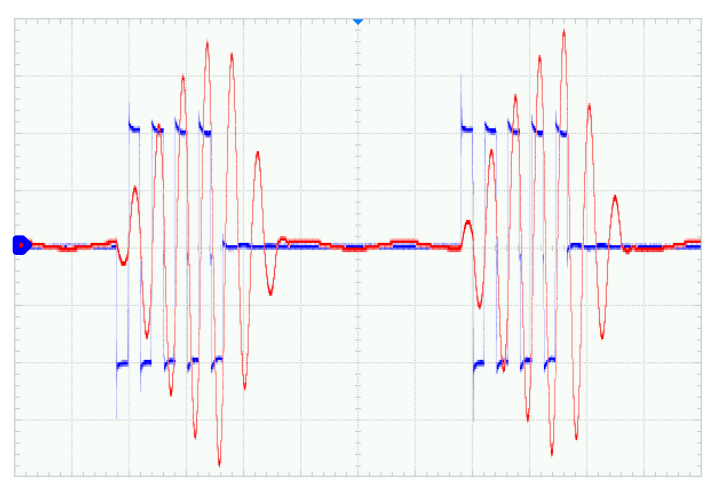

b)

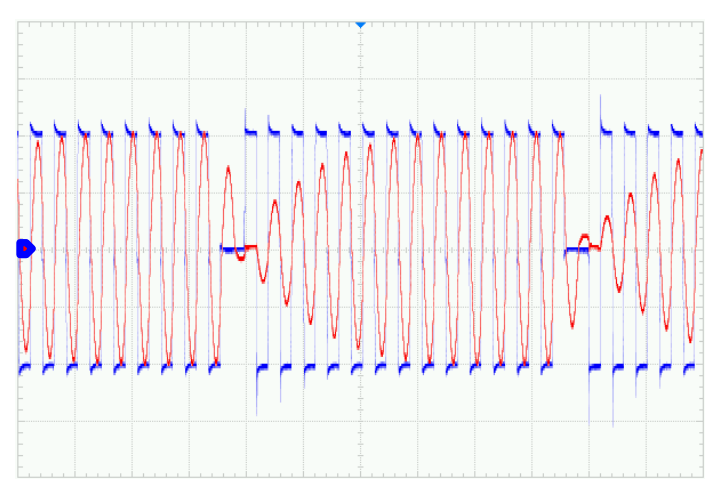

d)

Figure 12. The inverter voltage and current of PDM controlled converter for the different output currents (CH1: $100 \mathrm{~V}, \mathrm{CH} 2: 2 \mathrm{~A}$ and M: $20 \mu \mathrm{s}), a) 4 \mathrm{~A}, b) 6 \mathrm{~A}, c) 8 \mathrm{~A}, d) 10 \mathrm{~A}$

Although the switching frequency is selected above the resonance frequency to guarantee ZVS, in the first three cycles of the duty period of PDM, the current is not lagging and so soft switching conditions are disappeared. Therefore, the voltage stress on the ends of the power switches increases. The voltage and current waveforms of the switch $\mathrm{M}_{4}$ are given in Figure 13 for $10 \mathrm{~A}$. The zoomed version of the part shown with dashed lines in Figure 13a is given in Figure 13b. 


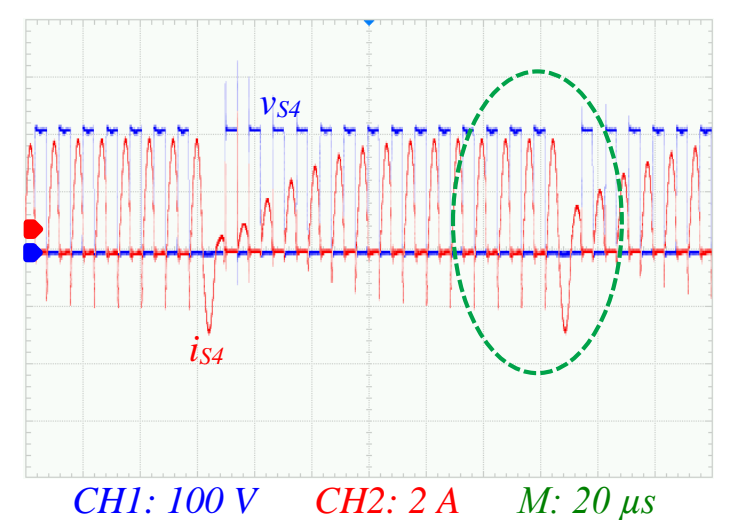

a)

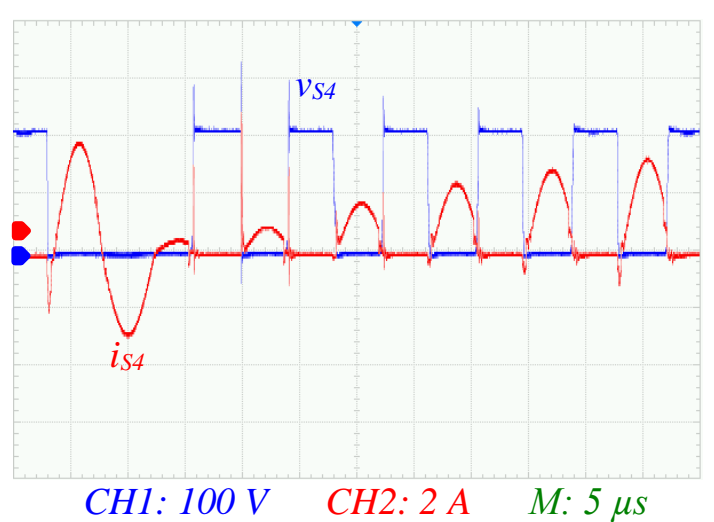

b)

Figure 13. The voltage and current of $M_{4}$ for $\left.10 \mathrm{~A}, a\right)$ the voltage and current of $\left.M_{4}, b\right)$ the zoomed voltage and current of $M_{4}$

The results summarizing the operation of PDM controlled converter for the different output currents are given in Table 4.

Table 4. Operation parameters of PDM controlled converter

\begin{tabular}{|c|c|c|c|c|c|c|c|c|}
\hline $\mathrm{V}_{\mathrm{i}}(\mathrm{V})$ & $\mathrm{I}_{\mathrm{i}}(\mathrm{A})$ & $\mathrm{V}_{\mathrm{O}}(\mathrm{V})$ & $\mathrm{I}_{\mathrm{O}}(\mathrm{A})$ & $\begin{array}{c}\text { Efficiency } \\
(\%)\end{array}$ & $\begin{array}{c}\Delta \mathrm{V}_{\mathrm{O}} / \mathrm{V}_{\mathrm{O}} \\
(\%)\end{array}$ & $\mathrm{I}_{\mathrm{Lm}}(\mathrm{A})$ & $\begin{array}{c}\text { Duty } \\
\text { Ratio (D) }\end{array}$ & $\begin{array}{c}\text { Switch } \\
\text { Stresses (V) }\end{array}$ \\
\hline 200 & 0.397 & 13.60 & 4.02 & 68.86 & 6.6 & 7 & 0.16 & 330 \\
\hline 200 & 0.580 & 17.00 & 5.02 & 73.57 & 5.8 & 8 & 0.22 & 340 \\
\hline 200 & 0.800 & 20.50 & 6.05 & 77.52 & 6.8 & 7.6 & 0.3 & 300 \\
\hline 200 & 1.060 & 23.80 & 7.03 & 78.92 & 6.3 & 7.6 & 0.39 & 335 \\
\hline 200 & 1.333 & 27.20 & 8.03 & 81.93 & 6 & 6.7 & 0.53 & 300 \\
\hline 200 & 1.610 & 30.50 & 9.04 & 85.63 & 5.9 & 5.2 & 0.68 & 300 \\
\hline 200 & 1.930 & 33.80 & 10.02 & 87.74 & 6.2 & 4.2 & 0.93 & 310 \\
\hline
\end{tabular}

The peak value of the current of PDM controlled converter is approximately three times higher than FM and PSM, especially for low output currents.

\subsection{Comparison of The Control Techniques}

The efficiency, output voltage ripple, current peak value and switch voltage curves versus the output current of the converter controlled separately by three techniques from 4 A to $10 \mathrm{~A}$ are given in Figure 14.

The results obtained from the studies and the curves in Figure 14 are presented comparatively as follows.

- While the highest efficiency is obtained with FM, the technique with the lowest converter efficiency is PSM.

- The technique with the lowest output voltage ripple is FM.

- While FM is the technique with the lowest peak value of the current, it is much higher in PDM compared to FM and PSM.

- The switch voltage stresses of FM controlled converter are lower compared to PSM and PDM controlled converter.

- In FM, the switches are turned on with ZVS in a wide range of the output current. In PDM, while ZVS conditions cannot be satisfied in the first cycles of the control signal, the switches are turned on under ZVS conditions in the following cycles. When the current is leading in PSM, ZVS conditions are disappeared for the two switches on the left arm. 
- While FM is the simplest and easiest technique for implementation, PDM is the most difficult one.

- Among the techniques, while FM has the least hardware, PDM has the most hardware because it requires the additional logic circuits other than DSC.

- In terms of the power control, PDM has disadvantageous according to the other two techniques because the resolution of the output power depends on the frequency of the control signal and audible sounds are produced when the frequency of the control signal is selected below $20 \mathrm{kHz}$.

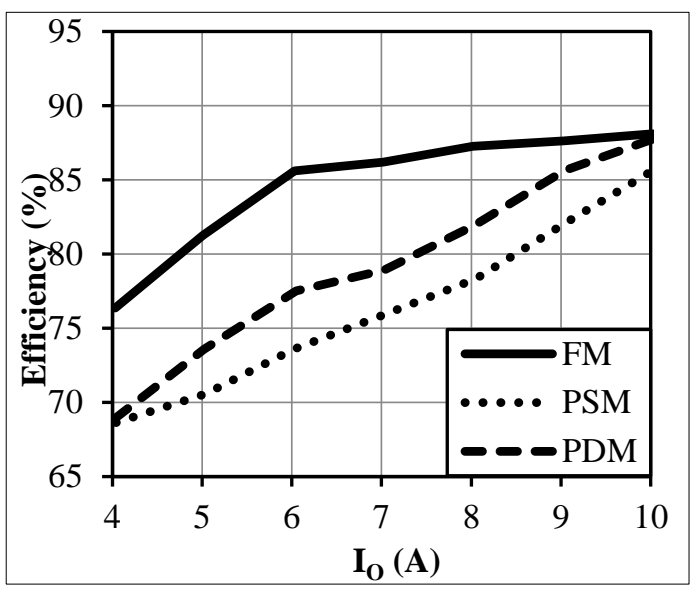

a)

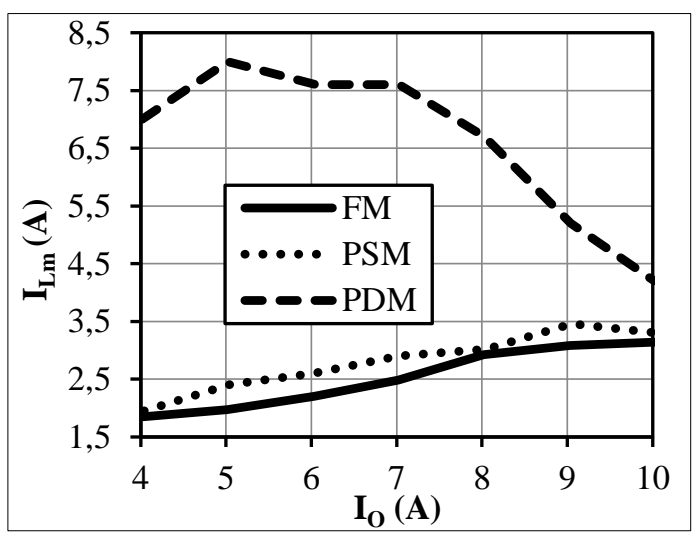

c)

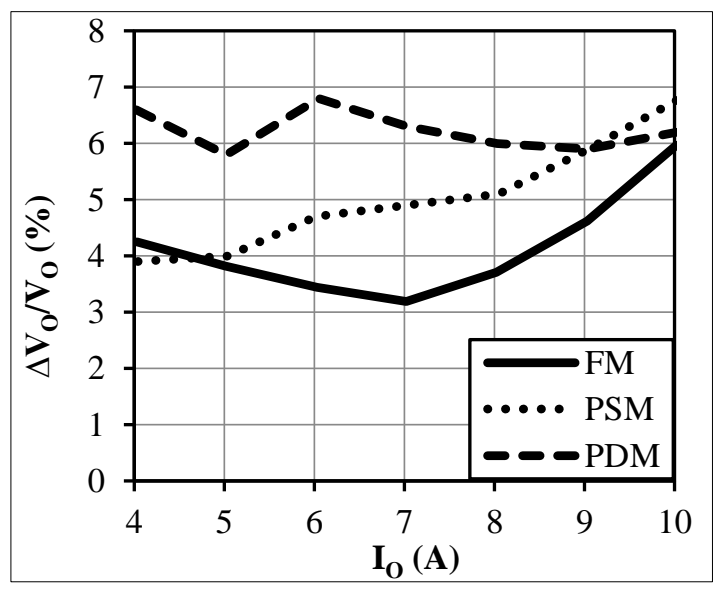

b)

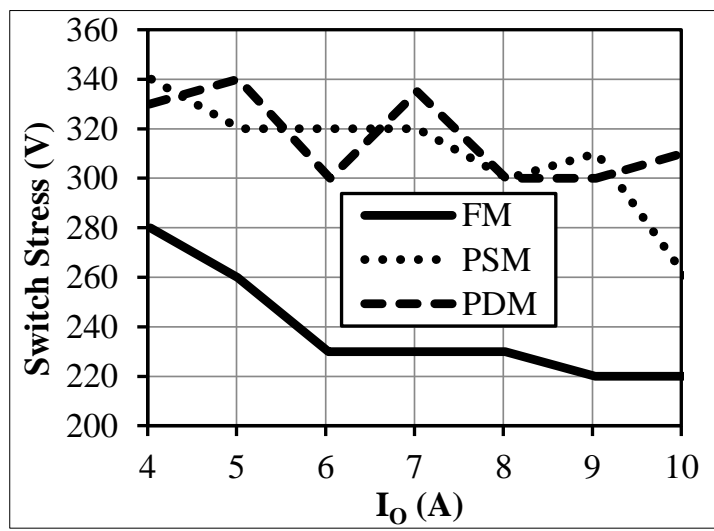

d)

Figure 14. The efficiency, output voltage ripple, current peak value and switch voltage curves versus the output current, a) efficiency, b) output voltage ripple c) current peak value, d) switch voltage stresses

The summary of the examinations and comparisons for the three techniques is given in Table 5 . 
Table 5. Comparison of FM, PSM and PDM

\begin{tabular}{|l|c|c|c|}
\hline & \multicolumn{3}{|c|}{ Control technique } \\
\hline Comparison Futures & FM & PSM & PDM \\
\hline Application ease & Simple & Medium & Difficult \\
\hline Efficiency & High & Low & Low \\
\hline Hardware structure & Simple & Medium & Complex \\
\hline Switch voltage & Low & High & High \\
\hline Soft switching & Moderate & Poor & Moderate \\
\hline Output voltage ripple & Low & High & High \\
\hline Resonance current & Low & Medium & High \\
\hline Operating frequency & Variable & Fixed & Fixed \\
\hline Dynamic response & Fast & Fast & Slow \\
\hline
\end{tabular}

As can be seen from Table 5, there is no control technique that meets the positive aspects of all comparison parameters.

\section{CONCLUSIONS}

In the present study, full-bridge SRC, one of the basic applications of load resonant converters, is designed and built to compare FM, PSM and PDM control techniques. The converter is individually controlled by each of these techniques for different output currents. Except for the additional logic circuit of the PDM, the control of the converter by FM, PSM and PDM is performed via the low-cost DSC. As a result of the control processes repeated with each technique for different output currents, it is observed that these techniques affect the efficiency, the ripple level of the output voltage, the output response speed, the operation under soft switching conditions, the operating frequency, the power control and power switches selection of the converter. The advantages and disadvantages of these techniques, which are compared in many ways, are also determined. Consequently, although FM performs the power control by varying the switching frequency in a wide range, it is more advantageous than PSM and PDM in many ways. In future studies, the hybrid techniques combining the advantages of each technique can be used to control the converter and compared with FM, PSM and PDM techniques.

\section{ACKNOWLEDGMENTS}

This research was supported by Karabük University Research Fund (KBUBAP-17-DR-264).

\section{REFERENCES}

[1] Youseff, M.Z., Jain, P.K. (2004). A review and performance evaluation of control techniques in resonant converters. The 30th Annual Conference of the IEEE Industrial Electronics Society, 215221.

[2] Aboushady, A. A., Ahmed, K. H., Finney, S. J., Williams, W. (2013). Linearized large signal modeling, analysis and control design of phase-controlled series-parallel resonant converters using state feedback. IEEE Transactions on power electronics, 28(8), 3896-3911.

[3] Özbay, H., Karafil, A., Öncü, S. (2021). Sliding mode PLL-PDM controller for induction heating system. Turkish Journal of Electrical Engineering and Computer Sciences, 2021(29), 1241-1258. 
[4] Karafil, A., Özbay, H., Öncü, S. (2021). Comparison of regular and irregular 32 PDM patterns for induction heating. IET Power Electronics, 14(1), 78-89.

[5] Chen, Y., Xu, J., Wang, Y., Lin, L., Cao, J. (2019). A dual-carrier modulation technique for halfbridge resonant converter with wide soft-switching range. IEEE Transactions on Industrial Electronics, 66 (1), 223-232.

[6] Chen, Y., Xu, J., Gao, Y., Lin, L., Cao, J., Ma, H. (2019). Analysis and design of phase-shift pulsefrequency modulated full bridge LCC resonant converter. IEEE Transactions on Industrial Electronics, 67(2), 1092-1102.

[7] Guo, B., Zhang, Y., Zhang, J., Gao, J. (2018). Hybrid control strategy of phase-shifted full-bridge LLC converter based on digital direct phase-shift control. Journal of Power Electronics, 18(3), 802816.

[8] Zhou, Y., He, X., Shenge, L. (2021). Full-bridge resonant converter with hybrid control for wide input voltage range applications. Journal of Power Electronics, 21(1), 269-281.

[9] Hu, S., Li, X., Bhat, K.S. (2019). Operation of a bidirectional series-resonant converter with minimized tank current and wide ZVS range. IEEE Transactions on Power Electronics, 34(1), 904915.

[10] Li, G., Xia, J., Wang, K., Deng, Y., He, X., Wang, Y. (2019). Hybrid modulation of parallel-series LLC resonant converter and phase shift full-bridge converter for a dual-output DC-DC converter. IEEE Journal of Emerging and Selected Topics in Power Electronics, 7(2), 833-842.

[11] Zhu, J., Qian, Q., Lu, S, Sun, N. (2019). Phase-shift triple full-bridge ZVZCS converter with all soft switched devices. Journal of Power Electronics, 19(6), 1337-1350.

[12] Choi, J., Jung, J. (2020). Hybrid modulations strategy of three-phase dual-active-bridge converter to improve power conversion efficiency under light load conditions in LVDC applications. Journal of Power Electronics, 20(4), 894-903.

[13] Calleja, H., Pacheco, J. (2000). Frequency spectra of pulse-density modulated waveforms. 7th IEEE International Power Electronics Congress, 223-228.

[14] Fujita, H., Akagi, H. (1996). Pulse-density-modulated power control of a 4 kW, 450 kHz voltagesource inverter for induction melting applications. IEEE Transaction on Industry Applications, 32(2), 279-286.

[15] Nagarajan, B., Sathi, R.R. (2015). Phase locked loop based pulse density modulation scheme for the power control of induction heating applications. Journal of Power Electronics, 15(1), 65-77.

[16] Esteve, V., Sanchis-Kilders, E., Jordan, J., Dede, E.J., Cases, C., Maset, E., Ejea, J.B., Ferreres, A. (2015). Enchanced pulse-density-modulated power control for high-frequency induction heating inverters. IEEE Transaction on Industrial Electronics, 62(11), 6905-6914.

[17] Hammouma, C., Zeroug, H., Attab, A. (2018). Combined PDM with frequency-temperature profile adaptation control for induction metal hardening. 44th Annual Conference of the IEEE Industrial Electronics Society, 3485-3490.

[18] Herasymenko, P., Hutsaliuk, V., Pavlovskyi, V., Yurchenko, O. (2017). A software phase-locked loop of control system of a series-resonant voltage-source inverter for induction heating equipment. 2017 IEEE First Ukraine Conference on Electrical and Computer Engineering, 384-389.

[19] Sandali, A., Cheriti, A., Sicard, P (2004). Comparison of the various PDM control modes. 2004 IEEE International Conference on Industrial Technology, 574-579. 
[20] Fan, M., Shi, L., Yin, Z., Li, Y. (2017). A novel pulse density modulation with semi-bridgeless active rectifier in inductive power transfer system for rail vehicle. CES Transaction on Electrical Machines and Systems, 1(4), 397-404.

[21] Liu, Y. (2007). Design and implementation of an FPGA-based CCFL driving system with digital dimming capability. IEEE Transactions on Industrial Electronics, 54(6), 3307-3316.

[22] Oncu, S., Karafil, A. (2017). Pulse density modulation controlled converter for PV sytems. International Journal of Hydrogen Energy, 42(28), 17823-17830.

[23] Park, N., Lee, D., Hyun, D. (2007). A power-control scheme with constant switching frequency in class-D inverter for induction-heating jar application. IEEE Transaction on Industrial Electronics, 54(3), 1252-1260.

[24] Li, Y., Zhang, K., Yang, S. (2019). Multimode hybrid control strategy of LLC resonant converter in applications with input voltage range. Journal of Power Electronics, 19(1), 201-210.

[25] Suryawanshi, H.M., Pachor, S., Ajmal, T., Talapur, G.G., Sathyan, S., Ballal, M.S., Borghate, V.B., Ramteke, M.R. (2018). Hybrid control of high-efficient resonant converter for renewable energy system. IEEE Transactions on Industrial Informatics, 14(5), 1835-1845.

[26] Yeh, C., Chen, C., Lee, M., Lai, J. (2019). A hybrid modulation method for single-stage softswitching inverter based on series resonant converter. IEEE Transactions on Power Electronics, 35(6), 5785-5796.

[27] Sabate, J.A., Lee, F.C.Y. (1991). Offline application of the fixed-frequency clamped-mode series resonant converter. IEEE Transaction on Power Electronics, 6 (1), 39-47.

[28] Aboushady, A.A., Ahmed, K.H., Finney, S.J., Williams, B.W. (2010). Steady-state analysis of fullbridge series resonant converter with phase-shift and frequency control. 5th IET International Conference on Power Electronics, Machines and Drives, 1-6.

[29] Cavallaro, C., Cecconi, V., Chimento, F., Musumeci, S., Santonocito, C., Sapuppo, C. (2007). A Phase-Shift full bridge converter for the energy management of electrolyser systems. IEEE International Symposium, 2649-2654.

[30] Török, L., Nielsen, C.K., Munk-Nielsen, S., Romer, C., Flindt, P. (2015). High-efficiency electrolyzer power supply for household hydrogen production and storage systems. 17th European Conference on Power Electronics and Applications, 1-9.

[31] Babu, R.S.R., Henry, J. (2012). A Comparative Analysis of DC-DC Converters for Renewable Energy System. Proceedings of the international Multi conference of Engineers \& Computer Scientists, 1020-1025. 